\title{
Effect of underwater visual survey methodology on bias and precision of fish counts: a simulation approach
}

\author{
Miguel Pessanha Pais ${ }^{\text {Corresp., }}{ }^{1}$, Henrique N Cabral ${ }^{1}$ \\ ${ }^{1}$ MARE - Marine and Environmental Sciences Centre, Faculdade de Ciências, Universidade de Lisboa, Portugal \\ Corresponding Author: Miguel Pessanha Pais \\ Email address: mppais@fc.ul.pt
}

Bias in underwater visual census has always been elusive. In fact, the choice of sampling method and the behavioural traits of fish are two of the most important factors affecting bias, but they are still treated separately, which leads to arbitrarily chosen sampling methods. FishCensus, a two-dimensional agent-based model with realistic fish movement, was used to simulate problematic behavioural traits in SCUBA diving visual census methods and understand how sampling methodology affects the precision and bias of counts. Using a fixed true density of $0.3 \mathrm{fish} / \mathrm{m}^{2}$ and a fixed visibility of $6 \mathrm{~m}, 10$ counts were simulated for several combinations of parameters for transects (length, width, speed) and point counts (radius, rotation speed, time), generating trait-specific heatmaps for bias and precision. In general, point counts had higher bias and were less precise than transects. Fish attracted to divers led to the highest bias, while cryptic fish had the most accurate counts. For point counts, increasing survey time increased bias and variability, increasing radius reduced bias for most traits but increased bias in the case of fish that avoid divers. Rotation speed did not have a significant effect in general, but it increased bias for fish that avoid divers. Wider and longer transects and a faster swim speed are beneficial when sampling mobile species, but a narrower, shorter transect with a slow swim is beneficial for cryptic fish. 
1 Effect of underwater visual survey methodology on bias and precision of fish counts: a

2 simulation approach

3

4 Miguel Pessanha Pais ${ }^{1},{ }^{*}$, Henrique N. Cabral $^{1}$

$5{ }^{1}$ MARE - Marine and Environmental Sciences Centre, Faculdade de Ciências, Universidade de

6 Lisboa, Portugal

$7 \quad$ * Corresponding author: mppais@,fc.ul.pt

8 


\section{Abstract}

Bias in underwater visual census has always been elusive. In fact, the choice of sampling method and the behavioural traits of fish are two of the most important factors affecting bias, but they are still treated separately, which leads to arbitrarily chosen sampling methods. FishCensus, a twodimensional agent-based model with realistic fish movement, was used to simulate problematic behavioural traits in SCUBA diving visual census methods and understand how sampling methodology affects the precision and bias of counts. Using a fixed true density of $0.3 \mathrm{fish} / \mathrm{m}^{2}$ and a fixed visibility of $6 \mathrm{~m}, 10$ counts were simulated for several combinations of parameters for transects (length, width, speed) and point counts (radius, rotation speed, time), generating trait-specific heatmaps for bias and precision. In general, point counts had higher bias and were less precise than transects. Fish attracted to divers led to the highest bias, while cryptic fish had the most accurate counts. For point counts, increasing survey time increased bias and variability, increasing radius reduced bias for most traits but increased bias in the case of fish that avoid divers. Rotation speed did not have a significant effect in general, but it increased bias for fish that avoid divers. Wider and longer transects and a faster swim speed are beneficial when sampling mobile species, but a narrower, shorter transect with a slow swim is beneficial for cryptic fish.

\section{Introduction}

Underwater visual census (UVC) methods are used worldwide to survey shallow aquatic habitats and are particularly known for supporting conservation and fisheries management decisions on temperate and coral reefs (Caldwell et al., 2016). 
31 UVC methods can be generically classified into stationary point counts, transects and timed

32 swims. In a stationary point, a diver stays in the same spot and surveys a fixed radius for a given

33 time (Bohnsack \& Bannerot, 1986). In the transect, the diver swims in a straight line at a

34 constant speed for a given distance (or time) and counts organisms within a pre-determined transect width (Brock, 1954), or while estimating the distances to each organism (Thomas et al., 2006). On the timed swim, a diver swims along a random path, or changes direction at fixed intervals, counting organisms along the way (Jones \& Thompson, 1978; Kimmel, 1985). Each of these techniques has advantages and disadvantages, and some might be more suited for a particular purpose or species (Lincoln Smith, 1989; Kulbicki et al., 2010). In addition, UVC methods have different configurations, such as different transect lengths and widths, observation ranges or survey times. This results in a vast amount of combinations that may not be directly comparable, making this choice a very important one for future re-use of survey data (Sale \& Sharp, 1983; Cheal \& Thompson, 1997; Kulbicki et al., 2010). However, criteria for choosing a UVC method are often independent of the research question, purpose or species of interest, and are deeply rooted in local tradition or institutional adoptions for long-term studies (Caldwell et al., 2016). This contrasts with the fact that UVC performance is deeply linked to species

47 behavioural traits (Sale \& Sharp, 1983; Kulbicki, 1998; MacNeil et al., 2008b; Bozec et al., 48 2011; Pais \& Cabral, 2017). For a sampling method, performance results from the combination of precision (dispersion of estimates) and bias (inaccuracy of estimates). A method that has great

50 precision should be favoured for hypothesis testing, while a method that leads to lower bias

51 should be used in biomass estimates for fisheries management or conservation (Trebilco et al.,

52 2011; Jones et al., 2015). 
53 There is a long history of efforts to understand how sampling performance is affected by

54 different species and methods in the field. Cryptic and biomimetic species tend to have low

55 detectability and thus lead to underestimation (Willis, 2001; Bozec et al., 2011), while schooling

56 species can be difficult to count accurately and can also lead to great variability in estimates

57 depending on whether or not a school is found on a particular sample (Christensen \&

58 Winterbottom, 1981; MacNeil et al., 2008b; Kulbicki et al., 2010). Shyness and boldness

59 towards observers is also a behavioural trait known to affect counts. The probability of

60 recounting bold fish is increased, while shy fish are more likely to be missed, as they are often

61 found farther away from the observer and therefore less detectable (Samoilys \& Carlos, 2000;

62 Bozec et al., 2011; Prato et al., 2017). This decay of detectability with distance is the foundation

63 of the distance sampling method applied in visual census of many organisms (Thomas et al.,

64 2010; Katsanevakis et al., 2012), but its application in UVC of fish is still uncommon (Caldwell

65 et al., 2016). Reasons for this include the difficulty of estimating distances underwater, the

66 proximity of the observer to the organisms being counted and visibility constraints, which

67 sometimes lead to the need to establish a hard limit on the observation area that is so close to the

68 centre that a constant detection function can be assumed (Bozec et al., 2011). While focusing on

69 detectability, studies often ignore that UVC methods are usually non-instantaneous, which can

70 lead to overestimated abundance of moving fish, as new fish enter the sample area after the

71 observation started. This source of bias is known and acknowledged, but very difficult to

72 measure in the field and has been mostly identified on computer simulations (Watson, Carlos \&

73 Samoilys, 1995; Ward-Paige, Flemming \& Lotze, 2010; Glennie, Buckland \& Thomas, 2015;

74 Pais \& Cabral, 2017). This effect has been shown to exceed the effects of behavioural traits in 
75 simulated transects and stationary points, except in the case of sedentary or cryptic species,

76 which are slow moving or stationary (Pais \& Cabral, 2017).

77 It has been repeatedly suggested that different species, or at least different behavioural traits, 78 should be approached with different methods, and this has been applied in some cases (De

79 Girolamo \& Mazzoldi 2001, Henriques et al. 2013, Pais et al. 2013, 2014, Prato et al. 2017).

80 However, choosing a method that minimises bias is not an easy task, particularly in the field,

81 where the true density of a species is very hard or impossible to quantify. Often field studies that

82 compare methods tend to assume one of them is at least more accurate (Sale \& Sharp, 1983;

83 Kimmel, 1985; St. John, Russ \& Gladstone, 1990; Edgar, Barrett \& Morton, 2004; Bennett et al., 84 2009), but it is difficult to ensure it is objectively accurate, since UVC methods are known to be 85 biased and other techniques used as "controls" (capture-resight, fishing gears, poisoning, baited 86 video, etc.) are also prone to errors (Caughley, 1974; Katsanevakis et al., 2012).

87 To identify a suitable method for a species, it is important to use a tool that can address bias due 88 to behaviour, but also due to non-instantaneous sampling, and this is where simulation tools can 89 be useful. In this study, the agent-based simulation model FishCensus (Pais \& Cabral, 2017) is 90 used to analyse the effect of various UVC sampling parameters (e.g. sampling unit dimensions, 91 observer speed) on bias and precision, both for strip transects and stationary point counts, and 92 identify the best solutions for fish with different behavioural traits.

\section{Materials and Methods}

\section{Model overview}


95 The FishCensus model simulates how different fish behaviours affect density estimates in

96

97

98 common underwater visual census methods. A flexible vector-based fish movement algorithm can be adjusted to match behavioural patterns of species or groups.

This study used version 2.0 of the FishCensus model, programmed in NetLogo 6 (Wilensky, 1999). A full description following the ODD (Overview, Design concepts, Details) protocol for describing individual-based models (Grimm et al., 2010) is available in Pais \& Cabral (2017), as supplemental material to this paper (article S1) and in the COMSES repository

(https://www.comses.net/codebases/5305/), where the latest version of the model, all source code and documentation are available.

The model is spatial, two-dimensional and has two types of moving agents, divers and fish. The model landscape is represented by a grid of squares with $1 \mathrm{~m}$ sides that have no variables directly affecting agents. Depth is ignored (assumed constant) and maximum underwater visibility was set to 6 metres and remained constant. This is a common, albeit low-end visibility for UVC, but it is still adequate for surveys and limits sampling unit sizes to a region where constant detectability with distance can be assumed (Bozec et al., 2011). The landscape size was set to 20 x 80 squares $\left(1600 \mathrm{~m}^{2}\right)$ to allow for enough buffer space outside the sample area. Fish wrap around when they reach the edges to avoid artificial gathering near walls. There are two levels on the time scale. Fish and diver movements use a time step representing $1 / 10$ of a second and all other procedures in the model are based on a time step of one second.

Fish movement is based on the sum of vectors that define "urges" (avoid diver, align with schoolmates, centre position in school, schoolmate spacing, wander, rest, cruise). The magnitude of the urge vectors can be weighted to rank them in terms of importance, and these weights are stored as fish attributes. Another important fish attribute for the movement model is a constant 
118 used to estimate friction drag that is calculated from fish size and creates a deceleration vector. A

119 weighted sum of all the urge vectors at every time step determines the velocity vector on the next

120 time step (Wilensky, 2005). A description of all vectors is available in the full description (article

121 S1). A set of weights for all vectors defines a behavioural state, and fish can have up to four

122 states stored in a list, each with an associated probability (e.g. a "searching" state would give

123 more weight to the urge to wander randomly). If the fish has more than one behavioural state on

124 its repertoire, a new one is picked every 10 model seconds based on a weighted random pick

125 with replacement, so a very frequent behaviour can be picked multiple times sequentially. A

126 detectability parameter can also be set, establishing the probability of being visible to the diver.

127 Whether a fish is hidden from the diver is decided after a behaviour change, for every fish

128 independently, as a Bernoulli trial based on detectability.

129 At the start of the simulation, fish are randomly placed on the environment, with a random

130 heading. Every fish picks the first behaviour on the repertoire and the movement submodel is run

131 for 200 cycles (20 model seconds) before the diver is placed to stabilise initial fish locations and

132 form schools when applicable. A diver performing a transect moves forward at a pre-determined

133 speed, while during stationary point counts the diver rotates clockwise on a fixed point with a

134 pre-defined angular speed, also every 1/10 of a second. Every second, the diver counts fish

135 within the area delimited by view angle, sample limits and maximum visibility. The diver

136 prioritises closest fish and counts with a saturation limit of 3 fish per second. Counted fish are

137 memorised and are not recounted while they remain visible (can be recounted if they leave and

138 re-enter the field of view). Once the diver has finished the sample, the model run is over, and

139 density is calculated by dividing the count by the sample area (width $\mathrm{x}$ distance for transects, $\pi$ *

140 radius $^{2}$ for point counts). At each replicate count, species locations are shuffled, and the outcome 
141 of their behaviours is different, ensuring not only stochasticity in model outputs, but also the

142 independence of replicates.

\section{Parameterisation of behavioural traits}

144 To understand the effect of sampling method parameters on inaccuracy, four generic types of

145 fish were created, representing behavioural traits that are known to affect accuracy on visual

146 census methods, namely a "schooling" type, a "cryptic" type, a fish that is attracted to divers and

147 a fish that evades divers ("bold" and "shy" types, respectively). For consistency we will use the

148 same fish types from Pais \& Cabral (2017), where a more detailed description can be found,

149 along with videos and a detailed analysis of the isolated effect of behaviour on bias and

150 precision.

151 Because urge vectors are an abstraction, and not something that can be directly measured,

152 parameterisation must be pattern-oriented (Grimm \& Railsback, 2012), based on the observable

153 behavioural patterns that emerge from a combination of parameters. This is made easy by the

154 NetLogo interface tools used to build FishCensus, where urge vector weights can be altered

155 while the model is running. All four fish types were parameterised based on real species or

156 families that are familiar to the authors, so that observation experience could aid in model

157 parameterisation. Perception angle for cryptic fish was assumed to be $360^{\circ}$, due to the position of

158 the eyes on top of the head and the predominantly sedentary behaviour. For all other fish types, a

159 value of $320^{\circ}$ was adopted, since it encompasses both visual and lateral line perception, in

160

accordance with observations by Partridge and Pitcher (1980). ID distance, approach distance,

161 schooling distance and some behaviour frequencies and patterns were parameterised by

162 qualitatively matching behavioural patterns based on the authors' experience from more than 250

163 UVC dives in temperate reefs, complemented by underwater video. 
164 The schooling type is based on sparids from the genus Diplodus. These species usually form 165 small schools and can be found shoaling on rock patches (Gonçalves et al., 2014). The cryptic 166 type is based on blenniids from the genus Parablennius. These are small benthic fish that hide in 167 crevices and males can have territorial behaviour in the reproductive season. Behaviours and 168 frequencies were based on a study by Almada et al. (1987) and detectability values were based 169 on MacNeil et al. (2008b). Both the shy and bold types share parameters from labrids from the 170 genus Labrus. These species are solitary and reaction to divers varies with species and life stage.

171 In the absence of available data on fine-scale behavioural states and frequencies for the 172 schooling, bold and shy types, these had to be roughly estimated from field experience which, in 173 this case, is not a big concern if the general characteristics of the behavioural traits are present 174 (e.g. Diplodus spp. are found stationary or shoaling more frequently than Labrus spp.).

175 The maximum cruise and burst speed values were calculated using the equations from Sambilay 176 Jr. (1990) from the caudal fin aspect ratio of representative fish species extracted from FishBase 177 online database (Froese \& Pauly, 2017). These were Parablennius pilicornis (Cuvier, 1829) for 178 the cryptic type, Diplodus vulgaris (Geoffroy Saint-Hilaire, 1817) for the schooling type and 179 Labrus bergylta Ascanius, 1767 for the shy and bold types.

180 Fixed attribute values for these types are specified in table 1 and behavioural states and 181 parameters for each type are summarised in table 2. Fish types are available as online 182 supplements in csv format and can be directly used as input files for the model (data S1, S2, S3 183 and S4).

\section{Experiment}


186 To understand the direction and strength of the effect of sampling method parameters on bias and

187 precision, 5 values were picked for each of the 3 parameters in transects and 5 values for time

188 and rotation speed for stationary point counts, while radius only varied in integers between 2 and

1895 , since a radius of 1 metre would be dominated by the effect of diver presence, and a radius of 6

190 would match the visibility limit, which is unrealistic for field studies (table 3).

191 Given that true density is unknown, Pais \& Cabral (2017) used different densities based on the 192 orders of magnitude found on previous field studies (e.g. Pais et al., 2014), concluding that 0.3

$193 \mathrm{fish} / \mathrm{m}^{2}$ ensured satisfactory computing performance while avoiding low baseline precision due 194 to rarity. Therefore, true density $\left(D_{t}\right)$ was fixed at $0.3 \mathrm{fish} / \mathrm{m}^{2}$ and 10 replicate runs were made 195 for each combination of parameters to calculate the average estimated density $\left(D_{e}\right)$ from the 196 simulated diver counts. Bias was calculated as the absolute difference from true density and 197 expressed as a proportion of true density:

$198 \delta=\left|\mathrm{D}_{\mathrm{e}}-\mathrm{D}_{\mathrm{t}}\right| / \mathrm{D}_{\mathrm{t}}$

199 Precision was calculated as the coefficient of variation of the estimated density from the 10

200 replicate counts and expressed as a percentage of true density.

201 The combined effects of all parameters on bias and precision were represented graphically using 202 heatmaps. The significance of effects on bias was tested using multiple linear regression models 203 including all main effects (3 parameters per method) and interactions, after appropriate 204 transformations to achieve linearity, normality of residuals and homoscedasticity on the full 205 model. Mild deviations from assumptions were tolerated. Residual variance was extracted from 206 the 10 replicate counts, and therefore the effects on precision were not tested for significance, as 207 a single coefficient of variation results from all replicates. All analyses were made using R 208 version 3.4.3 and the core stats package. 


\section{Results}

211

212

213

214

215

216

217

218

219

220

221

222

223

224

225

226

227

228

229

230

For this study we addressed bias as an absolute deviation from true density, however, data and summary figures that maintain negative bias values are available as supplemental files (data S5, fig. S1), where it is shown that most of the values were positive (overestimations), particularly for mobile fish.

Stationary point counts had a larger bias and less precision on average across all behavioural traits and parameters. For both methods, the bold trait led to larger bias and cryptic behaviour corresponded to the smallest bias values. Schooling behaviour led to low precision in estimates for both methods, although the bold trait had the highest average coefficient of variation in transects (table 4).

Figure 1 shows heatmaps of observed (not modelled) bias and precision for every combination of method parameters on transects and stationary point counts. Regression models had a good fit in general (multiple $\mathrm{R}^{2}>0.6$ ), except for the cryptic trait where $\mathrm{R}^{2}$ was approximately 0.4 for transects and 0.2 for point counts. However, since the effects observed in figure 1 for cryptic fish are generally monotonic, the significance tests are analysed. For detailed results of the linear regression models see supplemental table $\mathrm{S} 1$, and for raw response curves of bias and precision see figure S1. On stationary points (figure 1A), increasing survey time significantly increased bias for all behavioural traits, while increasing observation radius attenuates this effect for schooling, cryptic and bold fish. Shy fish count bias was not significantly affected by radius. High rotation speeds seem to slightly increase bias when a small radius is used, but overall the effect was not significant for schooling, cryptic and bold fish. On the other hand, bias increased 
231 with rotation speed for shy fish and was aggravated by long survey times and a large radius.

232 While the patterns observed for precision are less pronounced (figure 1C), it seems like many of

233 the parameters that tend to increase bias will also lead to higher variability. A long survey time

234 will in general lead to more imprecise estimates, particularly for a small radius. Increasing radius

235 tends to reduce variability, except for shy fish. Rotation speed does not seem to significantly

236 affect precision unless radius is small.

237 On transect surveys (figure 1B), a faster swim speed reduces bias for schooling, shy and bold

238 fish. Cryptic fish surveys benefit from slower swim speeds, particularly on narrower transects.

239 On the other hand, a narrower transect generates more bias for schooling, shy and bold fish.

240 Transect length does not seem to impact bias for schooling species, but it has a very slight but

241 significant effect in increasing bias for bold and shy species, particularly with slow speeds and

242 narrow transects. In the case of cryptic fish, the opposite pattern occurs, with length reducing

243 bias for slow and narrow transects. It is, however, evident in figure 1D that narrower, shorter

244 transects will generally lead to less precise estimates irrespective of behavioural traits.

245 Nevertheless, fast swim speeds usually increase precision and can attenuate this effect,

246 particularly on mobile species.

248 Discussion

249 This study has provided an insightful overview of the combined effects of different

250 methodological approaches in UVC, and how they differ for typically problematic behavioural

251 traits. In fact, this exercise seems to confirm that the system is more complex than what is

252 expected from an encounter probability model of randomly distributed moving objects, such as 
253 the Gerritsen-Strickler model (Gerritsen \& Strickler, 1977). This was also observed by Watson,

254 Carlos \& Samoilys (1995) with the Reefex model, even though they mostly focused on the effect

255 of speed and direction of fish. The present study helps establish a link between sampling method

256 and accuracy using more realistic behavioural traits, and it is clear from our results that accuracy

257 and encounter probability are not necessarily surrogates. In fact, Gerritsen and Strickler

258 demonstrated that a predator could either increase the search radius or the speed to increase

259 encounter probability, however, encountering more fish does not always mean being more

260 accurate, and this is where behaviour seems to have different effects. In case of a shy species,

261 increasing speed seems to be beneficial, but increasing radius in point counts increases bias.

262 With cryptic fish, a faster transect will lead to more bias, while a wider radius is beneficial in

263 point counts. This ultimately means that a stationary point is not always a special case of a

264 transect with zero speed.

265 Dealing with the effect of behavioural traits is complex because they tend to affect different

266 components of bias in UVC. The choice of traits for this study covers probably the most

267 problematic cases for underwater surveys: fast movement can generate bias due to non-

268 instantaneous sampling (Watson, Carlos \& Samoilys, 1995; Ward-Paige, Flemming \& Lotze,

269 2010; Pierucci \& Cózar, 2015), cryptic behaviours or mimicry can lead to biased counts due to

270 low detectability (Willis 2001, MacNeil et al. 2008), and shyness or boldness can lead to bias

271 due to observer influence (Kulbicki, 1998; Dickens et al., 2011). All these sources combined are

272 very difficult to tackle and correct, and field methods usually tackle one or two components,

273 most of the times having to compare estimated abundances with estimated "true" abundances

274 (Sale \& Sharp, 1983; St. John, Russ \& Gladstone, 1990; Willis, Millar \& Babcock, 2000;

275 Bennett et al., 2009). 
276 The fact that bias was mostly positive seems to go against the common assumption that UVC

277 methods always underestimate (Willis, 2001; Colvocoresses \& Acosta, 2007; Minte-Vera, de

278 Moura \& Francini-Filho, 2008). In fact, it seems obvious to assume that if some fish avoid divers

279 and others are hidden or missed, we must be underestimating counts. However, since fish are

280 coming into the sample area that were not there at the start, it is easy to get overestimations

281 simply because of the non-instantaneous nature of UVC methods. This has been repeatedly

282 shown by simulations and it is known to be linked not only to the direction of fish crossing the

283 sample area (Watson, Carlos \& Samoilys, 1995), but mostly to fish speed relative to the observer

284 (Ward-Paige, Flemming \& Lotze, 2010; Pierucci \& Cózar, 2015; Pais \& Cabral, 2017). In fact,

285 Ward-Paige et al. (2010) estimated positive biases of 672 to $1100 \%$ in transect surveys for fish

286 swimming at 0.4 to $0.6 \mathrm{~m} / \mathrm{s}$ with an observer speed of $1 \mathrm{~m} / \mathrm{min}$., which falls within the orders of

287 magnitude found in this study. This is the reason why we found that a faster speed in transects

288 reduces bias for all mobile fish, by shifting observer speed towards fish speed. In the case of

289 nearly-stationary cryptic fish, however, a fast swim will simply reduce the probability of

290 detection and result in a slight underestimation (De Girolamo \& Mazzoldi, 2001). This confirms

291 the field observations by Lincoln Smith (1988), who seems to have correctly hypothesised that

292 higher values due to fish speed could be overestimations. For this reason, it is very important to

293 accurately parameterise fish speed on any simulation approach. In the case of FishCensus, fish

294 speeds are a highly sensitive parameter (Pais \& Cabral, 2017), and therefore they should be taken

295 from real measurements, or at least be calculated from the caudal fin aspect ratio of the species

296 using the equations from Sambilay Jr (1990), which can be done automatically in the model.

297 For the tested traits and across all combinations of sampling parameters, point counts had larger

298 bias and more variability in estimates than transects. This confirms the observation made with 
299 FishCensus by Pais \& Cabral (2017) using fixed dimensions with equal visibility and sample

300 area for the same traits, but apparently contradicts the observations by Watson \& Quinn II (1997)

301 with the Reefex model, where point counts tended to have lower bias than transects with moving

302 fish. However, the method simulated on the Reefex model was a top-down observation of a

303 circle (instead of a rotation on a cylinder), and fish were simulated with head-on movement,

304 which is known to significantly increase bias on transects (Watson, Carlos \& Samoilys, 1995).

305 In field studies comparing both methods, the general pattern is that point counts lead to higher

306 estimated densities. However, different interpretations exist for this observation, from

307 considering that higher is more accurate (Colvocoresses \& Acosta, 2007) to recognising the

308 possibility of overestimation (Kulbicki et al., 2010). Minte-Vera et al. (2008) found no

309 differences with the shape of the sampling unit, but opted for point counts due to higher cost-

310 effectiveness, also assuming that higher densities were better. In some cases, it is difficult to find

311 differences between methods simply because of high residual variability that results in low

312 statistical power (Samoilys \& Carlos, 2000). In our simulations, a sample size of 10 was adopted

313 as a compromise between feasibility in a field context and attained precision, an important aspect

314 to consider given the cost of each sampling unit.

315 The observation that bold traits lead to higher bias is generally understood in the literature and is

316 mainly due to an artificial gathering of a higher density of fish near the observer that leads to

317 overestimation. This is known to contribute to overvalued reserve effects where the same species

318 is more approachable and curious inside marine protected areas (Kulbicki, 1998; Willis, Millar \&

319 Babcock, 2000). An interesting pattern, which confirms previous simulations by Pais \& Cabral

320 (2017) and Ward-Paige et al. (2010), is that stationary territorial fish, even with probabilities of

321 detection as low as $10 \%$, led to the lowest amount of bias when compared to mobile species, 
322 since they did not suffer from the effect of non-instantaneity. However, most field studies

323 attempt to quantify UVC bias for cryptic fish, and one of the main reasons is that it is achievable.

324 Their site-attachment and approachability make them ideal to estimate bias in the field, be it

325 through poisoning (Willis, 2001), baited census (Stewart \& Beukers, 2000), or by using a known

326 number of golf balls as a proxy (Sayer \& Poonian, 2007). These studies are very useful, but are

327 focused on a single component of bias.

328 With a fixed sample size, increasing the area of the sampling unit will generally increase

329 precision (Minte-Vera, de Moura \& Francini-Filho, 2008), which was also confirmed by our

330 results. However, precision is also significantly affected by behavioural traits (Pais \& Cabral,

331 2017). Across all methodologies, schooling behaviour led to the lowest precision, as the

332 difference between counting or missing a school is usually of at least tens of individuals. In

333 transects, however, swimming across a larger area with a chance of attracting bold fish along the

334 way leads to a greater effect of this trait in reducing precision, as more encounters will lead to

335 much higher counts (Colvocoresses \& Acosta, 2007). This is particularly relevant when

336 establishing sample sizes for monitoring programs. Pais et al. (2014) and Jones et al. (2015)

337 observed how sites with flat or patchy habitat led to low precision in fish counts and thus

338 required a higher sample size to achieve the same power to detect changes. The fact that

339 schooling is a known strategy of many species occupying these habitats is another point in

340 favour of being precautious with sample sizes if resources allow. This means conducting a priori

341 power analysis with schooling and/or bold species in flat or patchy sites and then establishing the

342 sample size for all sites based on this reference.

343 This study illustrated the difficulty of objectively establishing methodologies based on field data

344 alone, as sample dimensions and observation times interacted with each other and with species 
345 behaviour. In point counts, increasing survey time increased not only bias but also variability.

346 This results from having a stationary observer counting mobile fish that enter the sampling unit.

347 As time passes, the estimated abundance will only tend to increase, eventually leading to

348 overestimation (St. John, Russ \& Gladstone, 1990; Watson \& Quinn II, 1997). This is similar to

349 the "first phase" and "edge effect" identified by Kulbicki et al. (2010) at the beginning and end

350 of transects, where the surveyor stays on the same spot for a longer period and counts fish that

351 gathered around during the setup phase, or new fish that keep coming into view and being

352 counted when the diver has already reached the end of the transect. This effect is not

353 incorporated into the current version of the FishCensus model, since the diver starts and finishes

354 the transect immediately, but it would certainly result in larger overestimations of mobile fish

355 with transects, particularly with bold traits.

356 Bias in point counts was reduced for most species by using a larger radius, and the same was

357 observed when increasing width in transects. In fact, several field studies have observed that

358 density estimates are lower when the sample unit area increases (Sale \& Sharp, 1983;

359 Colvocoresses \& Acosta, 2007; Minte-Vera, de Moura \& Francini-Filho, 2008; Prato et al.,

360 2017). This tends to occur not only because there may be a reduction of detectability with

361 distance for some species (Bozec et al., 2011; Katsanevakis et al., 2012), but also because the

362 increase in area may not be proportionately met by an increase in fish numbers within that area,

363 and a slightly higher count is divided by a much larger area (Colvocoresses \& Acosta, 2007).

364 Our results show that lower density estimates reduce bias for most species, since smaller units

365 were already overestimating counts. However, this is not the case for cryptic fish in transects,

366 where counting less fish results in an even larger underestimation, thus increasing absolute bias

367 (Lincoln Smith, 1989; Willis, 2001). For shy fish in point counts, the pattern is inverted. Since 
368 the diver is stationary and shy fish are keeping their distance (approximately $3 \mathrm{~m}$ in our case),

369 increasing the radius will result in a higher count, which increases overestimation as the diver

370 rotates and more fish enter the area.

371 In strip transects, besides the effect of observer speed, which we already discussed, transect

372 dimensions can also affect bias and precision. In general, the effect of transect length on bias was

373 not very strong, except in the case of slow swimming surveyors. In this case, a long transect

374 increased bias of mobile species by worsening the effects of non-instantaneity (Lincoln Smith,

375 1988; St. John, Russ \& Gladstone, 1990; De Girolamo \& Mazzoldi, 2001). On the other hand,

376 cryptic fish counts were slightly more accurate with long, slow transects, as the probability of a

377 fish becoming visible while the observer is still looking increases. Very short transects, on the

378 other hand, led to low precision. This is the result of a sample unit area that is too small to

379 capture the heterogeneity of fish distribution (Minte-Vera, de Moura \& Francini-Filho, 2008).

380 It is widely accepted that there is no universal method for all possible conditions and species.

381 However, even authors applying in-depth optimisation approaches with empirical data recognise

382 limitations due to the complexity of the system (Jones et al., 2015). In the end, a single value for

383 the estimated density of a species is the result of the relative position of several fishes and one

384 surveyor in space and time, bounded by a combination of parameters that define a sample unit.

385 Where other analytical or field methods struggle to capture this complexity, agent-based spatial

386 simulations thrive, making them potential candidates as decision-support tools.

387 Simulations, however, are not a replacement of the real system, and this approach should be

388 complementary to field experiments. This does not necessarily mean fitting or validating the

389 model with field data, given that it was created because of a real value that is unknown, but

390 rather using the model to help interpret real observed patterns, as we did repeatedly in this 
391 discussion. While modelling facilitates understanding by simplifying the system, it requires

392 certain assumptions. In the case of FishCensus, the lack of individual variability in terms of size

393 and behavioural repertoire, absence of habitat complexity, two-dimensional representation and a

394 rather unforgiving implementation of diver memory can be pointed out as the main simplifying

395 assumptions (Pais \& Cabral, 2017).

396 It should also be noted that we used a single species approach. While single species assessments

397 are common in fisheries management surveys (Gardner \& Struthers, 2013), often whole

398 community assessments are important, which include even more sources of bias (Lincoln Smith

399 1989, De Girolamo \& Mazzoldi 2001, Babcock et al. 2012, Henriques et al. 2013, Pais et al.

400 2014). Besides the surveyor having to focus on a larger number of fish, which will likely favour

401 the most conspicuous (Willis, 2001), there is also species, age and gender-specific distribution

402 and behavioural traits (MacNeil et al. 2008, Kulbicki et al. 2010). The FishCensus model

403 supports multiple "fish types" simultaneously, but a single species assessment was deemed more

404 adequate and advantageous, not only because this reduces computing time, but also because it

405 isolates the particularities of each behavioural trait, so they can then be sampled together if

406 similarly affected by the choice of method.

\section{Conclusions}

408 To minimise bias in underwater visual surveys, our results suggest that a relatively large radius

409 and short time should be favoured in point counts, keeping in mind that rotation speed will not

410 have a marked effect in these conditions. A large radius will increase bias for shy fish, but if

411 survey time is short, it should not be significant. In the case of strip transects, swimming fast

412 along a wide transect favours smaller bias for mobile species. For cryptic species, a slow swim 
413 along a narrow transect should be favoured. It should be noted that very narrow and very short

414 transects will lead to less precision due to the small size of the sampling unit.

415 Our results support an objective approach to sampling design in UVC, not only in terms of the 416 amount of replication required (Pais et al., 2014; Jones et al., 2015), but also starting on the 417 sampling methodology itself. Abandoning traditional methods can disrupt long time series, but 418 probably in most cases we can afford a change that will benefit future surveys (Caldwell et al., 419 2016). The recognition of this problem is evident as new approaches are proposed to address the 420 shortcomings of established methods (Minte-Vera, de Moura \& Francini-Filho, 2008; Kruschel 421 \& Schultz, 2010; Prato et al., 2017). Using at least two different methods for multispecies 422 assessments (Lincoln Smith, 1989; De Girolamo \& Mazzoldi, 2001) is supported by our 423 findings. In this case a survey should start with a faster scan of a larger area for mobile species, 424 and then move on to a more focused, slower approach on a smaller area for sedentary, smaller 425 species. This makes the reasonable assumption that the diver presence on the first observation 426 period does not significantly affect subsequent counts of site-attached species (Sayer \& Poonian, 427 2007).

428 It must be stressed that the results obtained apply to the particularities of the species that inspired 429 each behavioural trait. Ideally, one should attempt to replicate the behaviour of the exact species 430 of interest as realistically as possible within the model, and then use it to optimise, plan and 431 interpret field surveys.

\section{Acknowledgements}


434 The authors acknowledge everyone who tested the model and interface, Christine Ward-Paige

435 for suggestions and discussions regarding the AnimDens model, Uri Wilenksy for NetLogo and

436 code snippets for vector-based swarming, Kenneth A. Rose for valuable feedback and

437 suggestions on an early version of the model and João G. Rosa for revising the calculation of 438 drag forces.

\section{References}

441

442

443

444

445

446

447

448

449

450

451

452

453

454

Almada V., Garcia G., Santos R. 1987. Padrões de actividade e estrutura dos territórios em machos parentais de Parablennius pilicornis (Cuvier) (Pisces: Blenniidae), da costa portuguesa. Análise Psicológica 2:261-268.

Babcock RC., Egli DP., Attwood CG. 2012. Incorporating behavioural variation in individualbased simulation models of marine reserve effectiveness. Environmental Conservation 39:282-294. DOI: 10.1017/S0376892912000148.

Bennett RH., Götz A., Sauer WH., Cowley PD., Palmer RM. 2009. Optimisation of underwater visual census and controlled angling methods for monitoring subtidal temperate reef fish communities. African Journal of Marine Science 31:277-287. DOI: 10.2989/AJMS.2009.31.3.1.989.

Bohnsack JA., Bannerot SP. 1986. A Stationary Visual Census Technique for Quantitatively Assessing Community Structure of Coral Reef Fishes.

Bozec YM., Kulbicki M., Laloë F., Mou-Tham G., Gascuel D. 2011. Factors affecting the detection distances of reef fish: Implications for visual counts. Marine Biology 158:969- 
981. DOI: 10.1007/s00227-011-1623-9.

456

457

458

459

460

461

462

463

464

465

466

467

468

469

470

471

472

473

474

475

Brock VE. 1954. A preliminary report on a method of estimating reef fish populations. Journal of Wildlife Management 18:297-308.

Caldwell ZR., Zgliczynski BJ., Williams GJ., Sandin SA. 2016. Reef fish survey techniques: Assessing the potential for standardizing methodologies. PLOS ONE 11. DOI: 10.1371/journal.pone.0153066.

Caughley G. 1974. Bias in aerial survey. The Journal of Wildlife Management 38:921-933. DOI: $10.2307 / 3800067$

Cheal AJ., Thompson AA. 1997. Comparing visual counts of coral reef fish: implications of transect width and species selection. Marine Ecology Progress Series 158:241-248. DOI: $10.3354 / \operatorname{meps} 158241$.

Christensen MS., Winterbottom R. 1981. A correction factor for, and its application to, visual censuses of littoral fish. South African Journal of Zoology 16:73-79. DOI: 10.1080/02541858.1981.11447736.

Colvocoresses J., Acosta A. 2007. A large-scale field comparison of strip transect and stationary point count methods for conducting length-based underwater visual surveys of reef fish populations. Fisheries Research 85:130-141. DOI: 10.1016/j.fishres.2007.01.012.

Dickens LC., Goatley CHR., Tanner JK., Bellwood DR. 2011. Quantifying relative diver effects in underwater visual censuses. PLoS ONE 6:6-8. DOI: 10.1371/journal.pone.0018965.

Edgar GJ., Barrett NS., Morton AJ. 2004. Biases associated with the use of underwater visual census techniques to quantify the density and size-structure of fish populations. Journal of 
476

477

478

479

480

481

482

483

484

485

486

487

488

489

490

491

492

493

494

495

496

Experimental Marine Biology and Ecology 308:269-290. DOI:

10.1016/j.jembe.2004.03.004.

Froese R., Pauly D. 2017.FishBase. World wide web electronic publication. Available at www.fishbase.org (accessed February 1, 2017).

Gardner JPA., Struthers CD. 2013. Comparisons among survey methodologies to test for abundance and size of a highly targeted fish species. Journal of Fish Biology 82:242-262. DOI: $10.1111 /$ j.1095-8649.2012.03478.x.

Gerritsen J., Strickler JR. 1977. Encounter Probabilities and Community Structure in Zooplankton: a Mathematical Model. Journal of the Fisheries Research Board of Canada 34:73-82. DOI: 10.1139/f77-008.

De Girolamo M., Mazzoldi C. 2001. The application of visual census on Mediterranean rocky habitats. Marine Environmental Research 51:1-16.

Glennie R., Buckland ST., Thomas L. 2015. The effect of animal movement on line transect estimates of abundance. PLoS ONE 10. DOI: 10.1371/journal.pone.0121333.

Gonçalves AR., Silva MF., Vendrell CL., Almada VC. 2014. Agonistic behaviour and shoal composition of juvenile Diplodus sargus: first field observations. Environmental Biology of Fishes 98:1015-1021. DOI: 10.1007/s 10641-014-0334-8.

Grimm V., Berger U., DeAngelis DL., Polhill JG., Giske J., Railsback SF. 2010. The ODD protocol: A review and first update. Ecological Modelling 221:2760-2768. DOI: 10.1016/j.ecolmodel.2010.08.019.

Grimm V., Railsback S. 2012. Pattern-oriented modelling: a "multi-scope" for predictive 
497

498

499

500

501

502

503

504

505

506

507

508

509

510

511

512

513

514

515

516

517

518

systems ecology. Philosophical Transactions of the Royal Society B 367:298-310. DOI: 10.1098/rstb.2011.0180.

Henriques S., Pais MP., Batista MI., Costa MJ., Cabral HN. 2013a. Response of fish-based metrics to anthropogenic pressures in temperate rocky reefs. Ecological Indicators 25:6576. DOI: 10.1016/j.ecolind.2012.09.003.

Henriques S., Pais MP., Costa MJ., Cabral HN. 2013b. Seasonal variability of rocky reef fish assemblages: detecting functional and structural changes due to fishing effects. Journal of Sea Research 79:50-59. DOI: 10.1016/j.seares.2013.02.004.

St. John J., Russ G., Gladstone W. 1990. Accuracy and bias of visual estimates of numbers, size structure and biomass of a coral reef fish. Marine Ecology Progress Series 64:253-262. DOI: $10.3354 /$ meps064253.

Jones T., Davidson RJ., Gardner JPA., Bell JJ. 2015. Evaluation and optimisation of underwater visual census monitoring for quantifying change in rocky-reef fish abundance. Biological Conservation 186:326-336. DOI: 10.1016/j.biocon.2015.03.033.

Jones R., Thompson M. 1978. Comparison of Florida reef fish assemblages using a rapid visual technique. Bulletin of Marine Science 28:159-172.

Katsanevakis S., Weber A., Pipitone C., Leopold M., Cronin M., Scheidat M., Doyle TK., BuhlMortensen L., Buhl-Mortensen P., D’Anna G., de Boois I., Dalpadado P., Damalas D., Fiorentino F., Garofalo G., Giacalone VM., Hawley KL., Issaris Y., Jansen J., Knight CM., Knittweis L., Kröncke I., Mirto S., Muxika I., Reiss H., Skjoldal HR., Vöge S. 2012. Monitoring marine populations and communities: Methods dealing with imperfect detectability. Aquatic Biology 16:31-52. DOI: 10.3354/ab00426. 
519 Kimmel JJ. 1985. A new species-time method for visual assessment of fishes and its comparison

520 with established methods. Environmental Biology of Fishes 12:23-32. DOI:

521 10.1007/BF00007707.

522 Kruschel C., Schultz S. 2010. Lure-assisted visual census: A new method for quantifying fish 523 abundance, behaviour, and predation risk in shallow coastal habitats. Marine and $524 \quad$ Freshwater Research 61:1349-1359. DOI: 10.1071/MF10042.

525 Kulbicki M. 1998. How the acquired behaviour of commercial reef fishes may influence the 526 results obtained from visual censuses. Journal of Experimental Marine Biology and Ecology 222:11-30. DOI: 10.1016/S0022-0981(97)00133-0.

528 Kulbicki M., Cornuet N., Vigliola L., Wantiez L., Moutham G., Chabanet P. 2010. Counting 529 coral reef fishes: Interaction between fish life-history traits and transect design. Journal of 530 Experimental Marine Biology and Ecology 387:15-23. DOI: 10.1016/j.jembe.2010.03.003.

531 Lincoln Smith MP. 1988. Effects of observer swimming speed on sample counts of temperate 532 rocky reef fish assemblages. Marine Ecology Progress Series 43:223-231. DOI: $533 \quad 10.3354 /$ meps043223.

534 Lincoln Smith MP. 1989. Improving multiespecies rocky reefs fish censuses by counting 535 different groups of species using different procredures. Environmental Biology of Fishes $536 \quad 26: 29-37$.

537 MacNeil MA., Graham NAJ., Conroy MJ., Fonnesbeck CJ., Polunin NVC., Rushton SP., 538 Chabanet P., McClanahan TR. 2008a. Detection heterogeneity in underwater visual-census 539 data. Journal of Fish Biology 73:1748-1763. DOI: 10.1111/j.1095-8649.2008.02067.x. 
540 MacNeil MA., Tyler EHM., Fonnesbeck CJ., Rushton SP., Polunin NVC., Conroy MJ. $2008 b$.

541 Accounting for detectability in reef-fish biodiversity estimates. Marine Ecology Progress

542 Series 367:249-260. DOI: 10.3354/meps07580.

543 Minte-Vera C V., de Moura RL., Francini-Filho RB. 2008. Nested sampling: an improved

544 visual-census technique for studying reef fish assemblages. Marine Ecology Progress Series

$545 \quad 367: 283-293$. DOI: $10.3354 / \operatorname{meps} 07511$.

546 Pais MP., Cabral HN. 2017. Fish behaviour effects on the accuracy and precision of underwater

547 visual census surveys. A virtual ecologist approach using an individual-based model.

$548 \quad$ Ecological Modelling 346:58-69. DOI: 10.1016/j.ecolmodel.2016.12.011.

549 Pais MP., Henriques S., Batista MI., Costa MJ., Cabral HN. 2013. Seeking functional

550 homogeneity: A framework for definition and classification of fish assemblage types to

551 support assessment tools on temperate reefs. Ecological Indicators 34:231-245. DOI:

$552 \quad$ 10.1016/j.ecolind.2013.05.006.

553 Pais MP., Henriques S., Costa MJ., Cabral HN. 2014. Topographic complexity and the power to 554 detect structural and functional changes in temperate reef fish assemblages: The need for 555 habitat-independent sample sizes. Ecological Indicators 45:18-27. DOI:

$556 \quad$ 10.1016/j.ecolind.2014.03.018.

557 Partridge BL., Pitcher TJ. 1980. The Sensory Basis of Fish Schools: Relative Roles of Lateral 558 Line and Vision. Journal of Comparative Physiology 135:315-325.

559 Pierucci A., Cózar A. 2015. An equation to estimate absolute population density from visual 560 census of mobile animals. Ecological Modelling 303:105-110. DOI:

$561 \quad$ 10.1016/j.ecolmodel.2015.02.017. 
562 Prato G., Thiriet P., Di Franco A., Francour P., Campbell S., Dawson T., Goldstien S. 2017.

563 Enhancing fish Underwater Visual Census to move forward assessment of fish assemblages:

564 An application in three Mediterranean Marine Protected Areas. Plos One 12:e0178511.

565 DOI: 10.1371/journal.pone.0178511.

566 Sale PF., Sharp BJ. 1983. Correction for bias in visual transect censuses of coral reef fishes.

$567 \quad$ Coral Reefs 2:37-42. DOI: 10.1007/BF00304730.

568 Sambilay Jr VC. 1990. Interrelationships between swimming speed, caudal fin aspect ratio and 569 body length of fishes. Fishbyte 8:16-20.

570 Samoilys MA., Carlos G. 2000. Determining methods of underwater visual census for estimating 571 the abundance of coral reef fishes. Environmental Biology of Fishes 57:289-304.

572 Sayer M., Poonian C. 2007. The influences of census technique on estimating indices of 573 macrofaunal population density in the temperate rocky subtidal zone. Underwater 574 Technology: The International Journal of the Society for Underwater 27:119-139. DOI: $575 \quad 10.3723 / 175605407783360053$.

576 Stewart B., Beukers J. 2000. Baited technique improves censuses of cryptic fish in complex 577 habitats. Marine Ecology Progress Series 197:259-272. DOI: 10.3354/meps 197259.

578 Thomas L., Buckland ST., Burnham KP., Anderson DR., Laake JL., Borchers DL., Strindberg S. 579 2006. Distance sampling. In: El-shaarawi AH, Piegorsch WW eds. Encyclopedia of .... 580 Chichester: John Wiley \& Sons, 544-552. DOI: 10.2307/2532812.

581 Thomas L., Buckland ST., Rexstad EA., Laake JL., Strindberg S., Hedley SL., Bishop JRB., 582 Marques TA., Burnham KP. 2010. Distance software: Design and analysis of distance 
583

584

585

586

587

588

589

590

591

592

593

594

595

596

597

598

599

600

601

602

603

sampling surveys for estimating population size. Journal of Applied Ecology 47:5-14. DOI: 10.1111/j.1365-2664.2009.01737.x.

Trebilco R., Halpern BS., Flemming JMJM., Field C., Blanchard W., Worm B. 2011. Mapping species richness and human impact drivers to inform global pelagic conservation prioritisation. Biological Conservation 144:1758-1766. DOI:

10.1016/j.biocon.2011.02.024.

Ward-Paige CA., Flemming JM., Lotze HK. 2010. Overestimating fish counts by noninstantaneous visual censuses: Consequences for population and community descriptions. PLoS ONE 5:e11722. DOI: 10.1371/journal.pone.0011722.

Watson RA., Carlos GM., Samoilys MA. 1995. Bias introduced by the non-random movement of fish in visual transect surveys. Ecological Modelling 77:205-214. DOI: 10.1016/03043800(93)E0085-H.

Watson RA., Quinn II TJ. 1997. Performance of transect and point count underwater visual census methods. Ecological Modelling 104:103-112. DOI: 10.1016/S0304-3800(97)001178.

Wilensky U. 2005. NetLogo flocking 3D alternate model. http://ccl.northwestern.edu/netlogo/models/Flocking3DAlternate. Evanston, IL, USA: Center for Connected Learning and Computer-Based Modeling, Northwestern University.

Willis TJ. 2001. Visual census methods underestimate density and diversity of cryptic reef fishes. Journal of Fish Biology 59:1408-1411. DOI: 10.1006/jfbi.2001.1721.

Willis TJ., Millar RB., Babcock RC. 2000. Detection of spatial variability in relative density of 
604 fishes: Comparison of visual census, angling, and baited underwater video. Marine Ecology 605 Progress Series 198:249-260. DOI: 10.3354/meps198249.

606 


\section{Figure 1}

Heatmaps of observed bias (\% difference from true density) and precision (coefficient of variation) for all combinations of parameters and behavioural traits.

Darker shades represent more bias and variation. Each square represents average bias extracted from 10 replicate runs and the coefficient of variation of the same 10 runs is used to represent precision. Shading is scaled to the range of each behavioural trait (table 4).

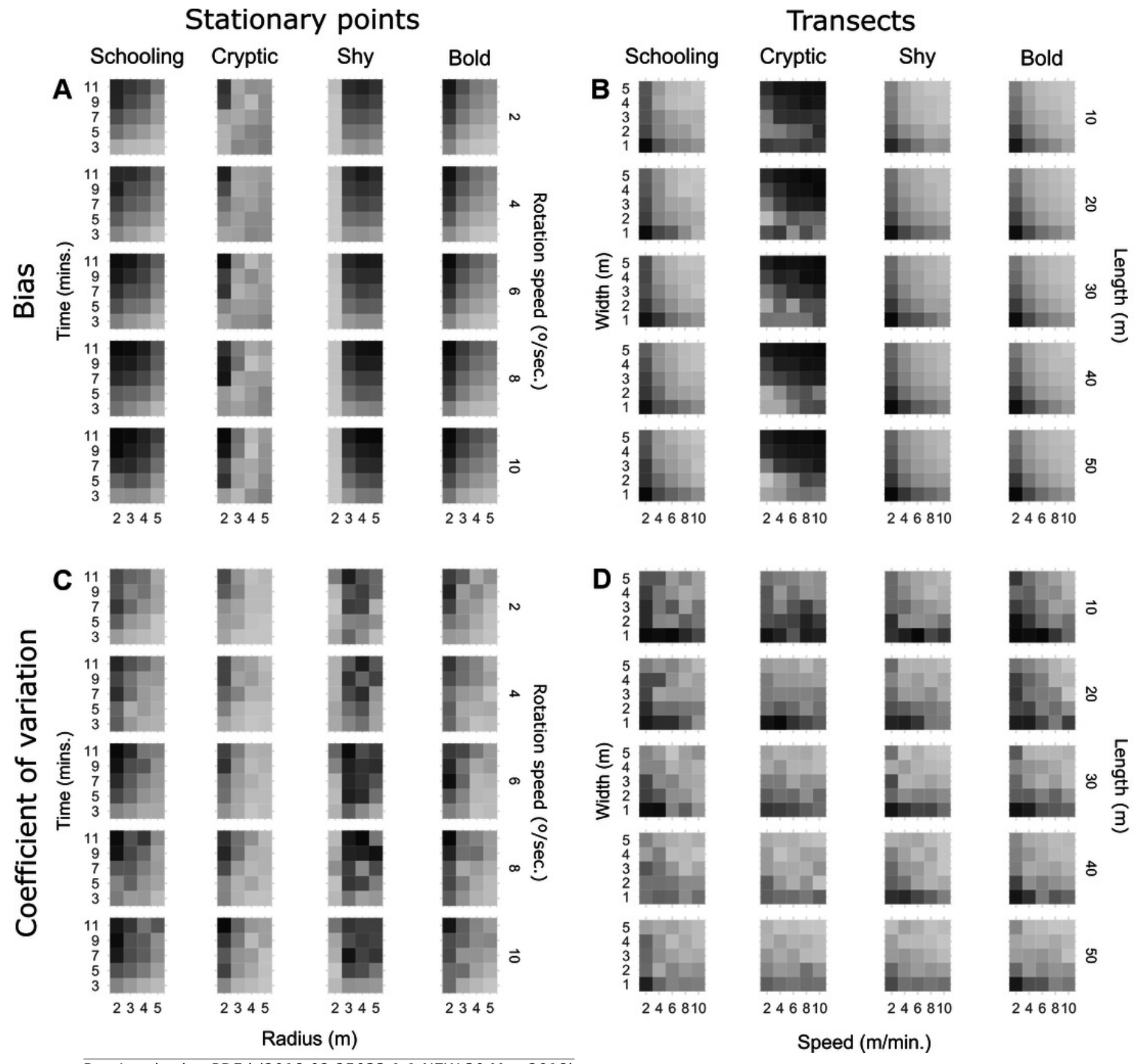




\section{Table 1 (on next page)}

Fixed attributes for the four types of fish used in the experiments (see text for details) 


\begin{tabular}{lllll} 
& Schooling & Cryptic & Shy & Bold \\
\hline Size $(\mathrm{m})$ & 0.2 & 0.1 & 0.3 & 0.3 \\
ID distance $(\mathrm{m})$ & 4 & 1 & 6 & 6 \\
Approach distance $(\mathrm{m})$ & 1.0 & 0.7 & 3.0 & 3.0 \\
Perception distance $(\mathrm{m})$ & 0.35 & - & - & - \\
Perception angle (degrees) & 320 & 360 & 320 & 320 \\
Max. acceleration $\left(\mathrm{m} / \mathrm{s}^{2}\right)$ & 0.2 & 0.1 & 0.1 & 0.1 \\
Max. sustained speed $(\mathrm{m} / \mathrm{s})$ & 0.5 & 0.3 & 0.4 & 0.4 \\
Burst speed $(\mathrm{m} / \mathrm{s})$ & 2.6 & 1.1 & 2.2 & 2.2 \\
\hline
\end{tabular}

1 


\section{Table 2 (on next page)}

Behavioural states, frequencies and attributes for the four fish types used in the experiments. (see text for details)

BL: body lengths 
1

\begin{tabular}{|c|c|c|c|c|}
\hline & & \multicolumn{3}{|l|}{ Schooling } \\
\hline & Behavioural state & wandering & feeding & stationary \\
\hline & Frequency & 0.5 & 0.2 & 0.3 \\
\hline & Detectability & 1 & 1 & 1 \\
\hline & Schooling? & TRUE & TRUE & TRUE \\
\hline & $\begin{array}{l}\text { Schooling } \\
\text { distance (BL) }\end{array}$ & 1 & 1 & 1 \\
\hline & $\begin{array}{l}\text { Patch distance } \\
\text { (m) }\end{array}$ & - & 1 & - \\
\hline \multirow{8}{*}{$\begin{array}{l}\text { Urge } \\
\text { weights }\end{array}$} & Align & 5 & 1 & 5 \\
\hline & Centre & 6 & 2 & 6 \\
\hline & Spacing & 15 & 5 & 15 \\
\hline & Wander & 3 & 1 & 1 \\
\hline & Rest & 0 & 1 & 7 \\
\hline & Cruise & 0 & 0 & 0 \\
\hline & Patch gathering & 0 & 10 & 0 \\
\hline & Diver avoidance & 10 & 10 & 10 \\
\hline
\end{tabular}

\begin{tabular}{llll}
\hline Cryptic & & & \\
\hline guarding & feeding & nested & patrolling \\
0.25 & 0.2 & 0.1 & 0.45
\end{tabular}

$\begin{array}{llll}0.25 & 0.2 & 0.1 & 0.45 \\ 0.3 & 0.6 & 0.1 & 0.5\end{array}$

0.3

FALSE FALSE FALSE FALSE

$-$

$\begin{array}{llll}0.5 & 3 & 0.5 & 2\end{array}$

$-$

$-$

3

2

0

6

4

\begin{tabular}{ll}
\hline Shy & \\
\hline wandering & stationary \\
0.6 & 0.4 \\
1 & 1 \\
FALSE & FALSE \\
- & - \\
- & -
\end{tabular}

\begin{tabular}{ll}
- & - \\
- & - \\
- & - \\
7 & 7 \\
0 & 6 \\
10 & 0 \\
0 & 0 \\
10 & 10 \\
\hline
\end{tabular}

wandering stationary

$0.6 \quad 0.4$

11

FALSE FALSE

- $\quad$

-

\begin{tabular}{ll}
\hline- & - \\
- & - \\
- & - \\
7 & 7 \\
0 & 6 \\
10 & 0 \\
0 & 0 \\
-1 & 0 \\
\hline
\end{tabular}




\section{Table 3(on next page)}

Range of parameter values used to test methodology effects on bias and precision 


\begin{tabular}{ll}
\hline Transect & values \\
\hline Length $(\mathrm{m})$ & $10,20,30,40,50$ \\
\hline Width $(\mathrm{m})$ & $1,2,3,4,5$ \\
\hline Swim speed $(\mathrm{m} / \mathrm{min})$. & $2,4,6,8,10$
\end{tabular}

\begin{tabular}{ll}
\hline Stationary & values \\
\hline Radius $(\mathrm{m})$ & $2,3,4,5$ \\
\hline Time (min.) & $3,5,7,9,11$ \\
\hline Turning angle (\%sec.) & $2,4,6,8,10$ \\
\hline
\end{tabular}

1 


\section{Table 4 (on next page)}

Average and range of bias and precision values per behavioural trait across all sampling parameter combinations.

Bias and coefficient of variation (CV) are in percentage of true density $\left(0.3 \mathrm{fish} / \mathrm{m}^{2}\right)$. 


\begin{tabular}{lcccc} 
& Stationary & \multicolumn{3}{l}{ Transect } \\
\cline { 2 - 5 } & Bias $(\%)$ & $\mathrm{CV}(\%)$ & Bias $(\%)$ & $\mathrm{CV}(\%)$ \\
\hline Schooling & 1182.3 & 317.7 & 215.2 & 71.3 \\
& $(130.8-2892.1)$ & $(41.8-1014.1)$ & $(41.0-871.3)$ & $(14.7-244.6)$ \\
\hline Cryptic & 83.0 & 62.5 & 49.2 & 14.2 \\
& $(25.6-307.3)$ & $(9.0-370.1)$ & $(14.3-79.7)$ & $(4.0-67.2)$ \\
\hline Shy & 758 & 89.7 & 387.3 & 52.6 \\
& $(23.6-2170.2)$ & $(33.5-202.9)$ & $(32.7-1730.0)$ & $(14.7-198.2)$ \\
\hline Bold & 2940.2 & 282.5 & 857.7 & 90.3 \\
& $(478.5-9181.4)$ & $(60.0-1082.8)$ & $(102.7-4200.7)$ & $(17.5-305.1)$ \\
\hline
\end{tabular}

1 